\title{
Prognostic Significance and Normal Values of 2D Strain to Assess Right Ventricular Systolic Function in Chronic Heart Failure
}

\author{
Soulef Guendouz, MD; Stéphane Rappeneau; Julien Nahum, MD; Jean-Luc Dubois-Randé, MD, PhD; \\ Pascal Gueret, MD, PhD; Jean-Luc Monin, MD, PhD; Pascal Lim, MD, PhD; \\ Serge Adnot, MD, PhD; Luc Hittinger, MD, PhD; Thibaud Damy, MD, PhD
}

\begin{abstract}
Background: Normal values and the prognostic significance of right ventricle (RV)-2D strain in chronic heart failure (CHF) patients are unknown.

Methods and Results: Between 2005 and 2010, we prospectively enrolled 43 controls and 118 stable CHF patients. Standard echocardiographic variables, tricuspid annular plane systolic excursion, peak systolic velocity of tricuspid annular motion using tissue Doppler imaging, and RV and left ventricle (LV) 2D-strain were measured. The primary outcome was death or emergency transplantation or emergency ventricular assist device implantation or acute heart failure. RV-2D strain was measurable in 39 controls ( $58 \pm 17$ years, $50 \%$ men), whose median value was $-30 \%$ (95\% confidence interval [ $95 \% \mathrm{Cl}],-39 \% ;-20 \%)$; and in $104 \mathrm{CHF}$ patients $(80 \%$ men, mean age $57 \pm 11$ years, and mean LV ejection fraction $29 \% \pm 8 \%)$, whose median value was $-19 \%(95 \% \mathrm{Cl},-34 \%$; $-9 \%)$. During the mean follow-up of $37 \pm 14$ months, 44 experienced the primary outcome. By Cox proportional hazards multivariate analysis, only RV-2D strain and log B-type natriuretic peptide independently predicted experiencing the primary outcome within the first year. The best RV-2D strain cut-off by receiver-operating characteristics analysis was $-21 \%$, and patients with values $>-21 \%$ were at greatest risk $\left(\chi^{2}\right.$-log-rank test $\left.=14.1, P<0.0001\right)$.
\end{abstract}

Conclusions: RV-2D strain is a strong independent predictor of severe adverse events in patients with $\mathrm{CHF}$ and may be superior to other systolic RV or LV echocardiographic variables. (Circ $J$ 2012; 76: 127-136)

Key Words: Echocardiography; Heart failure; Prognosis

$\mathbf{C}$ hronic heart failure (CHF) is an inexorably progressive condition that is ultimately fatal in the absence of cardiac transplantation. The identification of predictors of cardiac events in patients with CHF would help to optimize treatment decisions. Given the increasing prevalence of CHF, a method of accurately predicting cardiac events and suitable for use in everyday clinical practice is urgently needed.

\section{Editorial $\mathrm{p} \mathbf{4 3}$}

The right ventricle (RV) is pivotal in maintaining hemodynamic stability and an adequate cardiac output and recent studies point to a crucial role for RV systolic function in the course of several cardiovascular diseases. ${ }^{1,2}$ Over the past few years, RV systolic function has been proven in many studies to influence the prognosis of patients with CHF. ${ }^{3-5}$

Imaging studies that can be used to assess RV systolic function include echocardiography, angiography, radionuclide ventriculography, and magnetic resonance imaging., ${ }^{1,2}$ Of these, echocardiography is the most readily available and the most widely used in everyday clinical practice. Consequently, the identification of a simple echocardiographic parameter that reliably predicts outcomes in CHF would be of considerable interest. In several studies, selective systolic motion or contractility of the tricuspid annulus measured by M-mode echocardiography $\mathrm{y}^{4,6,7}$ or tissue Doppler imaging (TDI) were found to hold prognostic significance. ${ }^{8,9}$ Recently, 2D imaging of myocardial deformation, or strain, was found useful for assessing left ventricle (LV) function..$^{10}$ Angle-independent 2D strain imaging is now available on echocardiography systems and has been shown to reliably reflect RV function. Whether myo-

Received July 24, 2011; accepted September 12, 2011; released online October 27, 2011 Time for primary review: 18 days

Federation de Cardiologie (S.G., S.R., J.N., J.-L.D.-R., P.G., J.-L.M., P.L., L.H.), Service de Physiologie-Explorations Fonctionnelles (S.A.), AP-HP, Groupe Henri-Mondor Albert-Chenevier, Créteil; INSERM, Unité U955, Créteil (J.-L.D.-R., S.A., L.H., T.D.); and Faculté de Médecine and Université Paris-Est Val de Marne, Créteil F-94010 (J.-L.D-R., P.G., S.A., L.H., T.D.), France

The first two authors contributed equally to the study (S.G., S.R.).

Mailing address: Thibaud Damy, MD, PhD, Fédération de Cardiologie, Hôpital Henri Mondor, 51 Avenue Maréchal de Lattre de Tassigny,

94010 Créteil, France. E-mail: thibaud.damy@hmn.aphp.fr

ISSN-1346-9843 doi:10.1253/circj.CJ-11-0778

All rights are reserved to the Japanese Circulation Society. For permissions, please e-mail: cj@j-circ.or.jp 


\section{A}



B

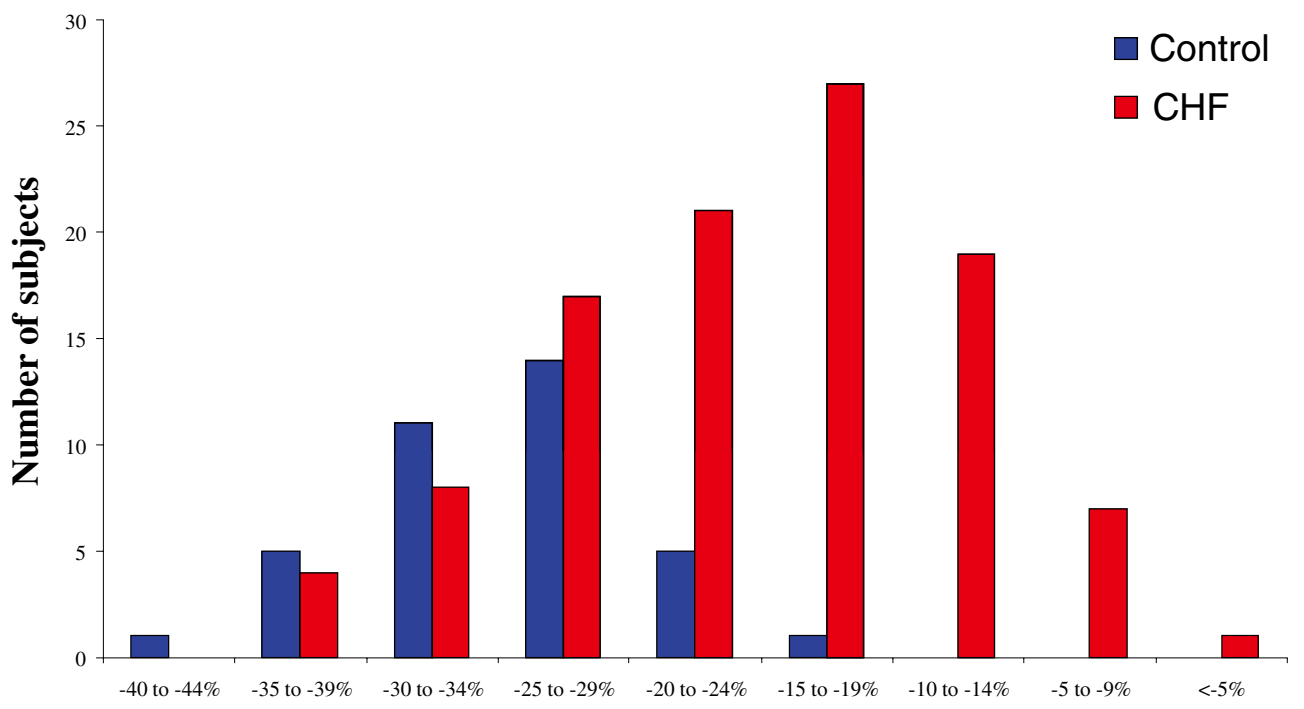

Class of RV 2D-strain, (\%)

Figure 1. (A) Study plan analysis. (B) Distribution of RV-2D strain value in controls and chronic heart failure (CHF) patients divided by class. $\mathrm{RV}$, right ventricle.

cardial deformation parameters derived from the RV supply additional information over standard echocardiography parameters in everyday clinical practice remains unknown. Furthermore, the normal 2D strain values for the RV have not yet been reported.11,12

Here, our objectives were to determine the normal values of $\mathrm{RV}-2 \mathrm{D}$ strain in healthy controls, the prognostic significance of RV-2D strain in patients with CHF, and the best RV-2D strain cut-off for identifying the high-risk patients with CHF.

\section{Study Population}

Between 2005 and 2010, we enrolled 118 patients receiving follow-up at our CHF clinics (CHU Henri Mondor, Créteil, France). Inclusion criteria were the use of appropriate medications, a clinically stable condition for at least the past month, and sinus rhythm. We also recruited, through advertising, 43 individuals free of cardiovascular disease and matching on age with the group of the patients, who served as the controls. 


\begin{tabular}{|c|c|c|c|c|c|c|}
\hline & $\begin{array}{c}\text { Controls } \\
(n=39)\end{array}$ & $\begin{array}{l}\text { All CHF } \\
(n=104)\end{array}$ & $\begin{array}{l}\text { P value } \\
\text { or } \chi^{2}\end{array}$ & $\begin{array}{c}\text { CHF, death } \\
\text { or emerg } \\
\text { transplan } \\
\text { device wi }\end{array}$ & $\begin{array}{l}\text { or acute HF } \\
\text { ncy heart } \\
\text { or assist } \\
\text { hin } 1 \text { year }\end{array}$ & $\begin{array}{c}\text { P value } \\
\text { or } \chi^{2} \\
\text { value }\end{array}$ \\
\hline & & & & Yes $(n=29)$ & No $(n=69)$ & \\
\hline \multicolumn{7}{|l|}{ Clinical characteristics } \\
\hline Age (years) & $50 \pm 15$ & $57 \pm 11$ & 0.06 & $62 \pm 11$ & $56 \pm 11$ & 0.11 \\
\hline Male, $\mathrm{n}(\%)$ & $21(54)$ & $83(80)$ & 0.005 & $36(82)$ & $47(78)$ & 0.66 \\
\hline $\mathrm{BMI}\left(\mathrm{kg} / \mathrm{m}^{2}\right)$ & $25 \pm 5$ & $26 \pm 5$ & 0.88 & $26 \pm 6$ & $26 \pm 4$ & 0.7 \\
\hline History of hypertension & - & $37(36)$ & & $9(21)$ & $28(47)$ & 0.006 \\
\hline Diabetes, n (\%) & - & $22(21)$ & & $9(21)$ & $13(22)$ & 0.88 \\
\hline Hypercholesterolemia, n (\%) & - & $56(54)$ & & $22(50)$ & $34(57)$ & 0.72 \\
\hline $\mathrm{SBP}(\mathrm{mmHg})$ & $137 \pm 16$ & $104 \pm 22$ & 0.0001 & $108 \pm 23$ & $107 \pm 21$ & 0.98 \\
\hline $\mathrm{DBP}(\mathrm{mmHg})$ & $74 \pm 10$ & $63 \pm 14$ & 0.09 & $66 \pm 4$ & $64 \pm 15$ & 0.82 \\
\hline Heart rate (beats/min) & $68 \pm 11$ & $74 \pm 14$ & 0.14 & $77 \pm 12$ & $71 \pm 15$ & 0.13 \\
\hline NYHA 3-4 vs. $1-2, n$ (\%) & 0 & $85(82)$ & 0.0001 & $39(89)$ & $46(77)$ & 0.12 \\
\hline Ischemic heart disease, $\mathrm{n}(\%)$ & 0 & $45(43)$ & 0.0001 & $20(46)$ & $25(42)$ & 0.7 \\
\hline \multicolumn{7}{|l|}{ Laboratory tests } \\
\hline Hemoglobin (g/dl) & $13.4 \pm 0.6$ & $13.6 \pm 1.7$ & 0.99 & $13.4 \pm 2.0$ & $13.9 \pm 1.7$ & 0.67 \\
\hline Creatinine $(\mu \mathrm{mol} / \mathrm{L})$ & $82 \pm 22$ & $118 \pm 51$ & 0.0001 & $128 \pm 27$ & $110 \pm 61$ & 0.08 \\
\hline $\mathrm{BNP}(\mathrm{pg} / \mathrm{ml})$ & $18 \pm 14$ & $373 \pm 539$ & 0.0001 & $660 \pm 662$ & $213 \pm 412$ & $<0.0001$ \\
\hline \multicolumn{7}{|l|}{ Treatment } \\
\hline$\beta$-blockers, $\mathrm{n}(\%)$ & - & $95(91)$ & & $39(89)$ & $56(93)$ & 0.4 \\
\hline ACE inhibitors, $n(\%)$ & - & $87(84)$ & & $38(86)$ & $49(82)$ & 0.52 \\
\hline AR inhibitors, $n(\%)$ & - & $20(19)$ & & $8(12)$ & $12(20)$ & 0.82 \\
\hline Diuretics, n (\%) & - & $90(87)$ & & $41(93)$ & $49(82)$ & 0.21 \\
\hline Aldosterone antagonist, $\mathrm{n}(\%)$ & - & $64(62)$ & & $27(61)$ & $37(62)$ & 0.98 \\
\hline
\end{tabular}

$\mathrm{CHF}$, chronic heart failure; HF, heart failure; BMI, body mass index; SBP, systolic blood pressure; DBP, diastolic blood pressure; NYHA, New York Heart Association; BNP, brain natriuretic peptide; ACE, angiotensin-converting enzyme; AR, angiotensin receptor.

The study complied with the Declaration of Helsinki. The local ethics committee approved the research protocol and informed consent was given by each study participant prior to inclusion.

\section{Study Assessments}

All study participants underwent the following: medical history, physical examination, blood tests (brain natriuretic peptide [BNP], creatinine, and hemoglobin), and a functional test (6-min walk test and/or cardiopulmonary testing).

All study participants underwent an echocardiographic examination at rest in the left lateral decubitus position. An experienced sonographer performed the examination using a Vivid 7 system (GE Vingmed, Horten, Norway). Standard parasternal views (long- and short-axis) and 4-chamber apical views were obtained. Four-chamber apical 2D grey-scale images were recorded with a frame rate $\geq 50$ per second. All data were stored digitally for off-line analysis using EchoPAC software (V7.0.0, GE Vingmed Ultrasound). Standard $\mathrm{RV}$ and LV function parameters were determined as recommended by the American Society of Echocardiography,,$^{13}$ and for each parameter the mean of 3 consecutive cardiac cycles was recorded. These parameters included RV end-diastolic area, RV end-sytolic area, RV fractional area, transcuspid annular plane systolic excursion (TAPSE) on the M-mode apical 4-chamber view, the tricuspid annular peak velocities using TDI ( $\mathrm{S}_{\mathrm{a}}, \mathrm{E}_{\mathrm{a}}$, and Aat waves), LV ejection fraction (LVEF), and LV end-diastolic diameter index to body surface area (LVEDDind). Early (Em) and late (Am) transmitral dia- stolic peak flow velocities and filling deceleration time were measured using pulsed-wave Doppler imaging of the mitral valve inflow. Peak accelerations of mitral annular velocity $\left(S_{a}\right.$, $\mathrm{E}_{\mathrm{a}}$, and $\mathrm{A}_{\mathrm{a}}$ waves) were also measured in the lateral and septal positions using TDI. Maximal tricuspid regurgitation velocity was determined and transtricuspid gradient calculated.

RV and LV peak systolic longitudinal strain and strain rate were assessed on the apical 4-chamber view using speckle tracking analysis. Patients whose RV-2D strain was not measurable were excluded from the analysis. Speckle tracking analyses motion by real-time tracking of the frame-to-frame movements of naturally occurring echo-dense speckles, using Echo-PAC software. The 2D strain and strain rate values can be derived by comparing the displacement of the speckles relative to each other throughout the cardiac cycle. For our study, the endocardial border was drawn manually and the region of interest (ROI) was generated automatically to include the entire myocardium. ROI position and width were adjusted manually when necessary. Segments with poor-quality tracking were discarded. The software automatically tracked the myocardial movements, dividing the myocardium into 6 segments. QRS onset is detected from the simultaneous ECG recording to define the time point when strain equals zero. The lateral $\mathrm{RV}$ wall and the septal and lateral $\mathrm{LV}$ walls were divided into basal, middle, and apical segments for computation of regional strain and strain rate values by the software as means per segment. Global longitudinal strain and global strain rate for the entire traced ventricular contour were computed and expressed as mean \pm SD. The standard echocardiographic 


\begin{tabular}{|c|c|c|c|c|c|c|}
\hline \multirow[b]{3}{*}{ LV variables } & \multirow[t]{3}{*}{$\begin{array}{c}\text { Controls } \\
(n=39)\end{array}$} & \multirow[t]{3}{*}{$\begin{array}{l}\text { All CHF } \\
(n=104)\end{array}$} & \multirow[t]{3}{*}{$P$ value } & \multicolumn{2}{|c|}{$\begin{array}{c}\text { CHF, death or acute HF } \\
\text { or emergency heart } \\
\text { transplant or assist } \\
\text { device within } 1 \text { year }\end{array}$} & \multirow[t]{3}{*}{$P$ value } \\
\hline & & & & \multirow[t]{2}{*}{ Yes $(n=29)$} & \multirow[t]{2}{*}{ No $(n=69)$} & \\
\hline & & & & & & \\
\hline LVEF (\%) & $59 \pm 9$ & $28 \pm 8$ & 0.0001 & $23 \pm 8$ & $30 \pm 7$ & $<0.001$ \\
\hline $\mathrm{Em}(\mathrm{cm} / \mathrm{s})$ & $70 \pm 16$ & $85 \pm 32$ & 0.14 & $95 \pm 26$ & $72 \pm 34$ & 0.001 \\
\hline $\mathrm{Am}(\mathrm{cm} / \mathrm{s})$ & $75 \pm 21$ & $55 \pm 28$ & 0.002 & $35 \pm 36$ & $57 \pm 25$ & 0.146 \\
\hline $\mathrm{Em} / \mathrm{Am}$ & $1.0 \pm 0.3$ & $1.3 \pm 1.5$ & 0.010 & $2.8 \pm 1.5$ & $1.1 \pm 1.4$ & 0.021 \\
\hline LVEDD $_{\text {ind }}\left(\mathrm{mm} / \mathrm{m}^{3}\right)$ & $25 \pm 4$ & $37 \pm 6$ & 0.0001 & $38 \pm 6$ & $37 \pm 6$ & 0.44 \\
\hline TDE (ms) & $228 \pm 39$ & $144 \pm 79$ & 0.001 & $117 \pm 57$ & $158 \pm 85$ & 0.008 \\
\hline Lateral $\mathrm{S}_{\mathrm{a}}(\mathrm{cm} / \mathrm{s})$ & $10.8 \pm 2.4$ & $5.0 \pm 1.9$ & 0.0001 & $4.6 \pm 1.6$ & $5.3 \pm 2.0$ & 0.063 \\
\hline Lateral $\mathrm{E}_{\mathrm{a}}(\mathrm{cm} / \mathrm{s})$ & $10.6 \pm 3.9$ & $5.7 \pm 2.8$ & 0.0001 & $6.0 \pm 3.4$ & $5.5 \pm 2.5$ & 0.349 \\
\hline Lateral $A_{a}(\mathrm{~cm} / \mathrm{s})$ & $11.4 \pm 1.3$ & $5.1 \pm 2.6$ & 0.0001 & $5.5 \pm 3.5$ & $5.0 \pm 2.1$ & 0.018 \\
\hline Septal $\mathrm{S}_{\mathrm{a}}(\mathrm{cm} / \mathrm{s})$ & $8.7 \pm 1.0$ & $4.0 \pm 1.9$ & 0.0001 & $3.7 \pm 1.3$ & $4.4 \pm 1.9$ & 0.049 \\
\hline Septal $E_{a}(\mathrm{~cm} / \mathrm{s})$ & $7.5 \pm 2.4$ & $4.2 \pm 2.2$ & 0.0001 & $5.0 \pm 2.5$ & $4.3 \pm 2.2$ & 0.863 \\
\hline Septal $A_{a}(\mathrm{~cm} / \mathrm{s})$ & $10.8 \pm 1.7$ & $5.1 \pm 2.5$ & 0.0001 & $3.6 \pm 2.5$ & $5.8 \pm 2.4$ & 0.004 \\
\hline $\mathrm{S}_{a}$ mean $(\mathrm{cm} / \mathrm{s})$ & $9.1 \pm 1.5$ & $4.4 \pm 1.6$ & 0.0001 & $4.1 \pm 1.2$ & $5.0 \pm 1.7$ & 0.019 \\
\hline $\mathrm{Em} / \mathrm{Ea}$ & $7 \pm 5$ & $14 \pm 10$ & 0.0001 & $18 \pm 11$ & $13 \pm 9$ & 0.05 \\
\hline \multicolumn{7}{|l|}{ RV variables } \\
\hline RVEDA $\left(\mathrm{cm}^{2}\right)$ & $17.3 \pm 3.6$ & $21.3 \pm 6.9$ & 0.045 & $23.4 \pm 8.0$ & $20.3 \pm 6.1$ & 0.038 \\
\hline $\operatorname{RVESA}\left(\mathrm{cm}^{2}\right)$ & $8.6 \pm 2.1$ & $14.2 \pm 6.8$ & 0.008 & $16.9 \pm 7.9$ & $13.1 \pm 6.0$ & 0.015 \\
\hline RV fractional area (\%) & $49.4 \pm 5.4$ & $36.4 \pm 13.4$ & 0.003 & $31.4 \pm 14.9$ & $38.4 \pm 12.2$ & 0.025 \\
\hline TAPSE (mm) & $25 \pm 4$ & $15 \pm 5$ & 0.0001 & $13 \pm 4$ & $17 \pm 5$ & 0.001 \\
\hline $\mathrm{S}_{a t}(\mathrm{~cm} / \mathrm{s})$ & $14.0 \pm 1.9$ & $9.0 \pm 2.8$ & 0.0001 & $7.5 \pm 2.2$ & $10.0 \pm 2.8$ & 0.0001 \\
\hline$E_{a t}(\mathrm{~cm} / \mathrm{s})$ & $12.0 \pm 3.0$ & $7.0 \pm 3.5$ & 0.0001 & $7.7 \pm 3.7$ & $6.9 \pm 3.4$ & 0.75 \\
\hline$A_{a t}(\mathrm{~cm} / \mathrm{s})$ & $14.0 \pm 3.2$ & $9.7 \pm 4.0$ & 0.0001 & $8.5 \pm 4.6$ & $10.1 \pm 3.5$ & 0.08 \\
\hline$E_{a t} / A_{a t}$ & $0.8 \pm 0.3$ & $0.7 \pm 0.8$ & 0.17 & $0.9 \pm 0.8$ & $0.7 \pm 0.8$ & 0.10 \\
\hline \multicolumn{7}{|l|}{ Pulmonary variables } \\
\hline TPG $(\mathrm{mmHg})$ & $15.4 \pm 0.9$ & $30.5 \pm 15.4$ & 0.0001 & $32.0 \pm 16.0$ & $28.4 \pm 14.9$ & 0.32 \\
\hline
\end{tabular}

Data are median \pm standard deviation.

LV, left ventricle; LVEF, left ventricular ejection fraction; $\mathrm{Em}, \mathrm{Am}$, early and late transmitral diastolic peak flow velocity, respectively; $\mathrm{Sa}, \mathrm{E}_{\mathrm{a}}, \mathrm{Aa}$, peak acceleration of annular velocity of $\mathrm{S}$, $\mathrm{E}$, and $\mathrm{A}$ wave, respectively, in lateral or septal position; LVEDDind, left ventricular end-diastolic diameter index to body surface area; TDE, deceleration time of $E$ wave $\mathrm{RV}$, right ventricle; RVEDA, right ventricle end-diastolic area; RVESA, right ventricle diastolic area; TAPSE, tricuspid annular plane systolic excursion; $\mathrm{S}_{\mathrm{at}}, \mathrm{E}_{\mathrm{at}}, \mathrm{A}_{\mathrm{a}}$, tricuspid annular peak velocity of $\mathrm{S}$, E and A wave, respectively; TPG, transtricuspid pulmonary gradient, measurable in 14 controls and $84 \mathrm{CHF}$ patients. Other abbreviations see in Table 1.

measurements, TDI, and off-line 2D strain and strain rate measurements were performed by a single sonographer, who was blind to the clinical data and outcome. Interobserver reproducibility was assessed in a random sample of 30 patients.

\section{Outcome Measures}

The primary endpoint was the occurrence of any of the following: death, urgent cardiac transplantation, urgent implantation of a ventricular assist device, and admission for acute heart failure requiring intravenous drug. Acute heart failure was defined as clinical sign of congestion (pulmonary edema or ankle edema or raised jugular venous pressure, ascites and/or hepatomegaly, all requiring intravenous diuretic treatment) or cardiogenic shock (sustained hypotension with tissue hypoperfusion requiring inotropic drugs). In each patient, only the event that occurred first was considered for the analysis, except when acute heart failure resulted during the same hospitalization in death or emergency surgery for cardiac transplantation or LV assist device implantation, in which case only the death or surgery was recorded. We only considered emergency surgery to avoid time-to-event bias because of organ donor availability or physician decision. Follow-up information was obtained either from the medical chart or by interviewing the patient. Patients who underwent elective cardiac transplantation or implantation of a ventricular assist device were censored at the time of surgery.

\section{Statistical Analysis}

Continuous variables were described as mean $\pm \mathrm{SD}$, except $\mathrm{BNP}$, which was described as median $\pm \mathrm{SD}$ (and logarithmically transformed for the other statistical analyses). The 2-tailed unpaired Student's test was used to compare means of continuous variables and the chi-square test (or Fisher's test where appropriate) to compare categorical variables. For this comparison CHF patients were divided into 2 groups based on whether they experienced the primary endpoint within 1 year of study inclusion. Patients without the primary endpoint who had less than 1 year of follow-up were excluded from this analysis $(n=6)$.

We performed a time-to-event analysis using a univariate Cox proportional hazard model including all the CHF patients $(n=104)$.Variables for which $P$ values in the univariate analy- 


\begin{tabular}{|c|c|c|c|c|c|c|}
\hline & $\begin{array}{c}\text { Controls } \\
(n=39)\end{array}$ & $\begin{array}{l}\text { All CHF } \\
(n=104)\end{array}$ & $P$ value & $\begin{array}{c}\text { CHF, death } \\
\text { or emerge } \\
\text { transplan } \\
\text { device wi }\end{array}$ & $\begin{array}{l}\text { or acute HF } \\
\text { ncy heart } \\
\text { or assist } \\
\text { hin } 1 \text { year }\end{array}$ & $P$ value \\
\hline & & & & Yes $(n=29)$ & No $(n=69)$ & \\
\hline \multicolumn{7}{|l|}{ LV 2D-strain, (\%) } \\
\hline \multicolumn{7}{|c|}{ Lateral wall segments } \\
\hline Basal & $-20.2 \pm 6.9$ & $-8.5 \pm 6.2$ & 0.0001 & $-8.2 \pm 5.9$ & $-8.3 \pm 6.3$ & 0.204 \\
\hline Middle & $-17.4 \pm 5.7$ & $-5.8 \pm 4.7$ & 0.0001 & $-4.8 \pm 4.8$ & $-7.3 \pm 4.7$ & 0.086 \\
\hline Apical & $-19.4 \pm 7.3$ & $-9.3 \pm 5.7$ & 0.0001 & $-10.2 \pm 4.0$ & $-9.5 \pm 6.3$ & 0.824 \\
\hline Mean & $-20.3 \pm 5.1$ & $-7.3 \pm 4.3$ & 0.0001 & $-6.6 \pm 3.6$ & $-8.0 \pm 4.5$ & 0.044 \\
\hline \multicolumn{7}{|c|}{ Septal wall segments } \\
\hline Basal & $-16.9 \pm 3.3$ & $-8.8 \pm 4.8$ & 0.0001 & $-7.5 \pm 4.0$ & $-9.8 \pm 5.0$ & 0.071 \\
\hline Middle & $-19.8 \pm 3.5$ & $-10.2 \pm 5.4$ & 0.0001 & $-8.7 \pm 6.1$ & $-10.8 \pm 5.0$ & 0.159 \\
\hline Apical & $-24.4 \pm 3.6$ & $-10.2 \pm 8.0$ & 0.0001 & $-9.9 \pm 6.2$ & $-11.0 \pm 8.7$ & 0.427 \\
\hline Mean & $-20.5 \pm 2.3$ & $-10.0 \pm 4.8$ & 0.0001 & $-8.6 \pm 4.9$ & $-10.9 \pm 4.6$ & 0.039 \\
\hline Mean 4C Strain & $-19.8 \pm 2.8$ & $-8.7 \pm 3.7$ & 0.0001 & $-8.4 \pm 3.2$ & $-9.5 \pm 3.7$ & 0.04 \\
\hline \multicolumn{7}{|c|}{ LV 2D-strain rate, per $0.1 \mathrm{~s}$} \\
\hline \multicolumn{7}{|c|}{ Lateral wall segments } \\
\hline Basal & $-1.6 \pm 0.6$ & $-0.9 \pm 0.5$ & 0.0001 & $-0.8 \pm 0.4$ & $-1.0 \pm 0.5$ & 0.336 \\
\hline Middle & $-1.1 \pm 0.4$ & $-0.5 \pm 0.3$ & 0.0001 & $-0.5 \pm 0.3$ & $-0.6 \pm 0.3$ & 0.223 \\
\hline Apical & $-1.3 \pm 0.5$ & $-0.7 \pm 0.4$ & 0.0001 & $-0.7 \pm 0.2$ & $-0.8 \pm 0.4$ & 0.172 \\
\hline Mean & $-1.36 \pm 0.39$ & $-0.77 \pm 0.30$ & 0.0001 & $-0.7 \pm 0.2$ & $-0.9 \pm 0.3$ & 0.087 \\
\hline \multicolumn{7}{|c|}{ Septal wall segments } \\
\hline Basal & $-1.0 \pm 0.3$ & $-0.8 \pm 0.4$ & 0.0001 & $-0.7 \pm 0.4$ & $-0.8 \pm 0.3$ & 0.925 \\
\hline Middle & $-1.1 \pm 0.2$ & $-0.7 \pm 0.3$ & 0.0001 & $-0.6 \pm 0.3$ & $-0.7 \pm 0.3$ & 0.153 \\
\hline Apical & $-1.4 \pm 0.3$ & $-0.8 \pm 0.4$ & 0.0001 & $-0.7 \pm 0.3$ & $-0.9 \pm 0.4$ & 0.097 \\
\hline Mean & $-1.23 \pm 0.23$ & $-0.73 \pm 0.27$ & 0.0001 & $-0.7 \pm 0.3$ & $-0.8 \pm 0.2$ & 0.044 \\
\hline Mean $4 \mathrm{C}$ Strain & $-1.35 \pm 0.24$ & $-0.72 \pm 0.23$ & 0.0001 & $-0.7 \pm 0.2$ & $-0.8 \pm 0.2$ & 0.024 \\
\hline \multicolumn{7}{|l|}{ RV 2D-strain, (\%) } \\
\hline \multicolumn{7}{|c|}{ Lateral wall segments } \\
\hline Basal & $-33.4 \pm 8.5$ & $-23.5 \pm 8.7$ & 0.0001 & $-18.5 \pm 7.5$ & $-24.3 \pm 9.0$ & 0.01 \\
\hline Middle & $-31.0 \pm 7.1$ & $-21.1 \pm 8.2$ & 0.0001 & $-16.7 \pm 7.0$ & $-22.9 \pm 8.4$ & 0.003 \\
\hline Apical & $-26.3 \pm 8.3$ & $-15.3 \pm 9.3$ & 0.0001 & $-12.8 \pm 8.3$ & $-18.8 \pm 8.7$ & 0.004 \\
\hline Mean & $-29.5 \pm 5.5$ & $-19.1 \pm 7.7$ & 0.0001 & $-15.7 \pm 6.3$ & $-21.3 \pm 7.9$ & 0.01 \\
\hline \multicolumn{7}{|c|}{ RV 2D-strain rate, per $0.1 \mathrm{~s}$} \\
\hline \multicolumn{7}{|c|}{ Lateral wall segments } \\
\hline Basal & $-2.79 \pm 0.75$ & $-1.72 \pm 0.66$ & 0.0001 & $-1.6 \pm 0.7$ & $-1.8 \pm 0.7$ & 0.40 \\
\hline Middle & $-2.12 \pm 0.45$ & $-1.42 \pm 0.51$ & 0.0001 & $-1.4 \pm 0.5$ & $-1.5 \pm 0.5$ & 0.077 \\
\hline Apical & $-1.67 \pm 0.5$ & $-1.21 \pm 0.51$ & 0.0001 & $-1.1 \pm 0.4$ & $-1.3 \pm 0.5$ & 0.095 \\
\hline Mean & $-2.11 \pm 0.4$ & $-1.44 \pm 0.44$ & 0.0001 & $-1.4 \pm 0.4$ & $-1.5 \pm 0.4$ & 0.18 \\
\hline
\end{tabular}

Data are median \pm standard deviation.

4C, 4-chamber; 2D, 2-dimensional. Other abbreviations see in Table 1.

sis were smaller than 0.05 were entered in a multivariate Cox proportional hazard model. Factors independently associated with the primary endpoint were identified using backward stepwise selection. We tested 3 models. The first model included the significant variables measuring RV systolic function and compared the strength of their associations with the primary endpoint. The second model included all significant echocardiographic variables and the third model all significant clinical, laboratory, and echocardiographic variables.

The accuracy of RV-2D strain for predicting the occurrence of the primary endpoint was assessed by computing the areas under the receiver-operating characteristic (ROC) curves (ROC-AUCs). The Youden test was performed to determine the best RV-2D strain cut-off. Finally, a Kaplan-Meier curve of event-free survival over time was constructed using the RV-2D strain cut-off. Values of P less than 0.05 were considered significant. Analyses were performed using SPSS 15.0 (SPSS Inc, Chicago, IL, USA).

\section{Results}

\section{Study Plan and RV-2D Strain Measurement Feasibility}

Figure 1A shows the study participant flow chart. We included 161 individuals, of whom 118 had CHF and 43 were controls. RV-2D strain was measurable in 39 (91\%) controls and 104 (88\%) CHF patients; only these 143 participants were included in the analysis. RV-2D strain was measurable in most of the lateral wall segments and measurement failures were most 


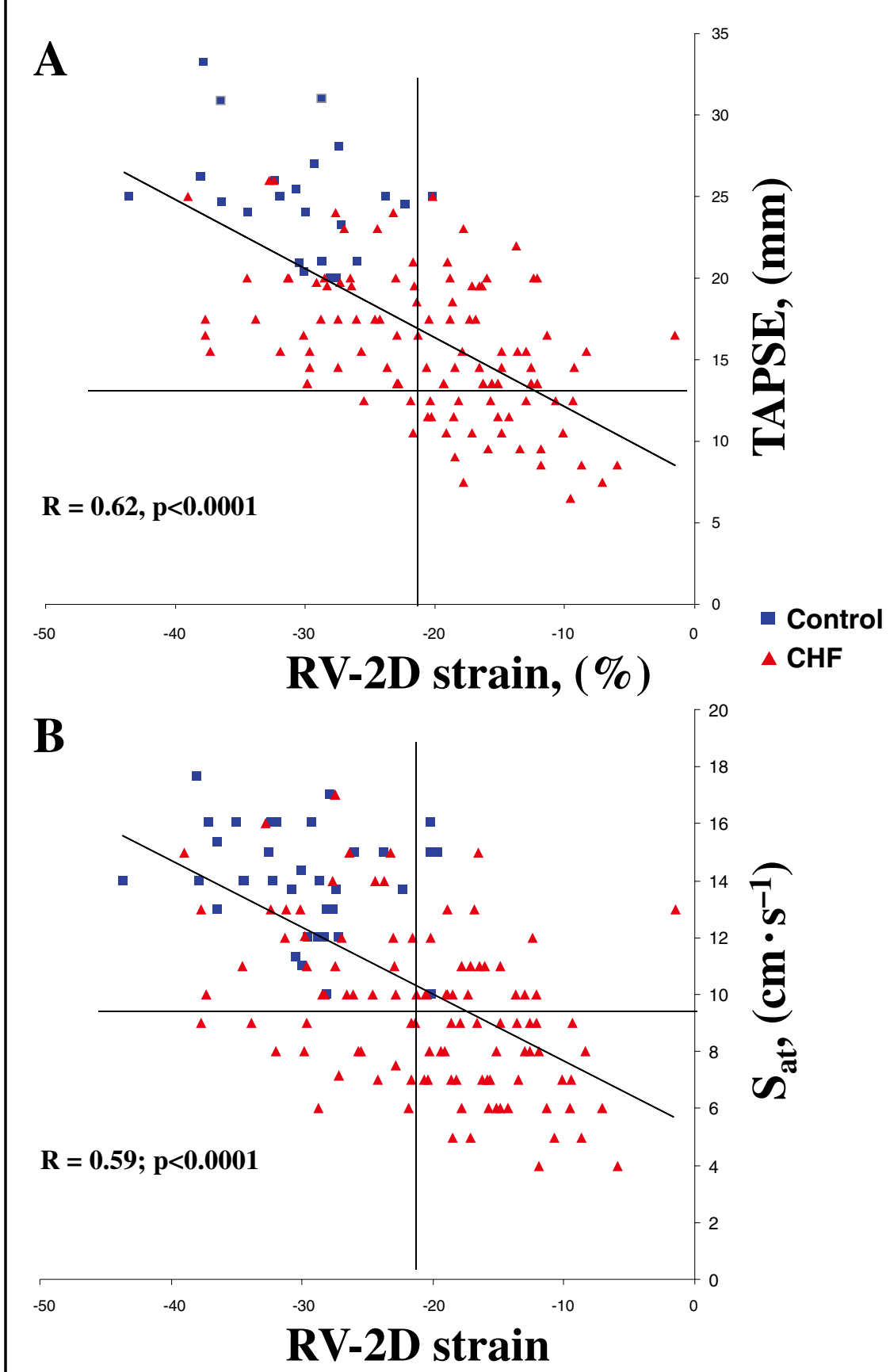

Figure 2. Correlation of RV-2D strain with (A) transcuspid annular plane systolic excursion (TAPSE) and (B) Sdti in controls (grey square) and chronic heart failure (CHF) patients (black triangle). RV, right ventricle.

common at the basal segment of the RV lateral wall of the controls (Figure 1A).

\section{Comparison of Baseline Characteristics of Controls and Patients}

Table 1 reports the main baseline clinical, laboratory, and treatment characteristics of the controls and CHF patients in whom RV-2D strain was measurable. Table 2 shows the Mmode, 2D, transmitral Doppler, and TDI of the LV and RV. The results in the CHF patients indicated severe impairment of $\mathrm{RV}$ and LV systolic functions and of LV diastolic function.

Table 3 reports the RV and LV 2D strain and strain rate data. For all variables, values were significantly lower in the control group than in the CHF group. Figure 1B shows the distribution of the RV-2D strain values. The median RV-2D strain value was $-30 \%$ (95\% confidence interval [95\% CI], $-39 \% ;-20 \%)$ in the controls and $-19 \%(95 \% \mathrm{CI},-34 \% ;-9 \%)$ in the patients with CHF. RV-2D strain correlated strongly with TAPSE and $\mathrm{S}_{\mathrm{a}}$, 2 echocardiographic variables known to reflect RV systolic function (Figure 2). 2D strain and strain rate values were higher for the RV than for the LV (Table 3).

\section{Comparison of CHF Patients Who Did or Did Not Experience the Primary Endpoint}

At last follow-up, 60 patients, with a mean follow-up of $33 \pm 13$ months, had not experienced the primary endpoint and 44 patients had (acute heart failure episode, $n=32$; other, $n=12$ ). Of the 60 patients without the primary endpoint, 5 underwent 


\begin{tabular}{|lcccc|}
\hline \multicolumn{5}{|c}{ Table 4. Univariate Analysis of Variables Associated With the Primary Outcome in the Group of Patients } \\
With CHF & Wald $\chi^{2}$ & P value & HR & $95 \%$ C \\
History of hypertension & 6.81 & 0.009 & 2.48 & $1.25 \pm 4.91$ \\
Log BNP (pg/ml) & 23.5 & 0.0001 & 6.08 & $2.93 \pm 12.6$ \\
LVEF (\%) & 19.8 & 0.0001 & 0.91 & $0.88 \pm 0.95$ \\
LV mean 4C strain (\%) & 6.52 & 0.011 & 1.14 & $1.03 \pm 1.25$ \\
LV mean 4C strain rate (\%) & 4.04 & 0.044 & 6.72 & $1.05 \pm 43.1$ \\
Sa mean (cm/s) & 12.3 & 0.0001 & 0.64 & $0.49 \pm 0.82$ \\
Em (cm/s) & 14.2 & 0.0001 & 1.01 & $1.00 \pm 1.02$ \\
Am (cm/s) & 3.98 & 0.046 & 0.99 & $0.98 \pm 1.00$ \\
Em/Am & 11.2 & 0.001 & 1.38 & $1.14 \pm 1.66$ \\
Em/Ea & 9.81 & 0.002 & 1.04 & $1.01 \pm 1.06$ \\
LVEDDind (mm/m²) & 4.09 & 0.043 & 1.05 & $1.00 \pm 1.11$ \\
E wave deceleration time (ms) & 12.9 & 0.0001 & 0.99 & $0.98 \pm 0.96$ \\
RV fractional area (\%) & 5.8 & 0.016 & 0.97 & $0.95 \pm 0.99$ \\
TAPSE (mm) & 4.46 & 0.035 & 0.93 & $0.87 \pm 1.00$ \\
Sat (cm/s) & 7.69 & 0.006 & 0.85 & $0.76 \pm 0.95$ \\
RV-2D strain (\%) & 11.4 & 0.001 & 1.07 & $1.03 \pm 1.12$ \\
RV-2D strain rate, per 0.1 s & 4.1 & 0.043 & 2.14 & $1.03 \pm 4.47$ \\
TPG (mmHg) & 2.8 & 0.09 & 1.02 & $0.99 \pm 1.04$ \\
\hline
\end{tabular}

$\mathrm{HR}$, hazard ratio; $\mathrm{Cl}$, confidence interval; $\mathrm{S}_{a}, \mathrm{E}_{\mathrm{a}}, \mathrm{A}_{\mathrm{a}}$, peak acceleration of annular velocity of $\mathrm{S}$, $\mathrm{E}$, and $\mathrm{A}$ wave, respectively, in lateral or septal position; Sat, peak systolic velocity of the tricuspid annular; TPG, transtricuspid pulmonary gradient, measurable in $84 \mathrm{CHF}$ patients. Other abbreviations see in Tables 1-3.

\begin{tabular}{|c|c|c|c|c|}
\hline Model & Wald $\chi^{2}$ & $P$ value & HR & $95 \% \mathrm{Cl}$ \\
\hline \multicolumn{5}{|c|}{$\begin{array}{l}\text { Model 1: RV systolic function variables (RVEDA, RV } \\
\text { fractional area, RV strain, RV strain rate, TAPSE, S) }\end{array}$} \\
\hline RV 2D-strain & 11.2 & 0.001 & 1.08 & $1.03 \pm 1.13$ \\
\hline \multicolumn{5}{|c|}{ Model 2: Echocardiographic variables } \\
\hline RV 2D-strain & 6.54 & 0.011 & 1.08 & $1.02 \pm 1.15$ \\
\hline LVEDDind & 4.51 & 0.034 & 1.076 & $1.05 \pm 1.13$ \\
\hline E wave deceleration time & 3.65 & 0.06 & 0.99 & $0.98 \pm 0.99$ \\
\hline \multicolumn{5}{|c|}{$\begin{array}{l}\text { Model 3: Clinical, laboratory, and echocardiographic } \\
\text { variables }\end{array}$} \\
\hline Log BNP & 16.85 & 0.0001 & 5.04 & $2.33 \pm 10.92$ \\
\hline RV 2D-strain & 4.93 & 0.045 & 1.05 & $1.00 \pm 1.10$ \\
\hline
\end{tabular}

Abbreviations see in Tables 1-4.

elective heart transplantation and 2 had elective implantation of an LV assist device.

Of the $104 \mathrm{CHF}$ patients, 98 had completed at least 1 year of follow-up, $29 \mathrm{CHF}$ patients had experienced the primary outcome and 69 had not. The baseline characteristics of these 98 CHF patients are shown in Tables 1-3. The only significant clinical or treatment difference at baseline was a higher prevalence of hypertension in the subgroup with the primary outcome. This subgroup also had worse RV and LV systolic functions, with higher values for BNP and Em/Am and lower values for LVEF. The subgroup with the primary outcome had higher mean values for LV-2D strain of the lateral segments and basal segments and for the mean of these 2 variables, compared with the CHF subgroup without the primary outcome. Segment-by-segment comparisons showed no significant differences between the 2 subgroups. The subgroup with the primary outcome within 1 year had significantly higher values for mean septal LV-2D strain rate and the mean of the septal- and lateral-segment strain rates. RV-2D strain values for the $3 \mathrm{RV}$ wall segments were significantly higher in the subgroup with the primary outcome than in the subgroup without the primary outcome after 1 year. In contrast, the 2 subgroups were not significantly different regarding the RV-2D strain rate values.

Prognostic Significance of Strain and Strain Rate Values Tables 4 and $\mathbf{5}$ show the results of the univariate and multivariate Cox proportional hazard model analyses. RV-2D strain was a better predictor of the primary outcome than the other echocardiographic variables measuring RV systolic function (TAPSE and S) or LV function (LVEF and E/Ea). RV-2D strain remained significantly associated with the primary outcome when all the clinical, laboratory, and echocardiographic variables were added to the model. The best RV-2D strain cut-off for separating CHF patients with and without the primary outcome within 1 year was $-21 \%$. Interestingly, $96 \%$ of the controls and $56 \%$ of the CHF patients had RV strain values below this cut-off. The Kaplan-Meier with RV-2D strain cut- 


\section{Primary endpoint in CHF patients}

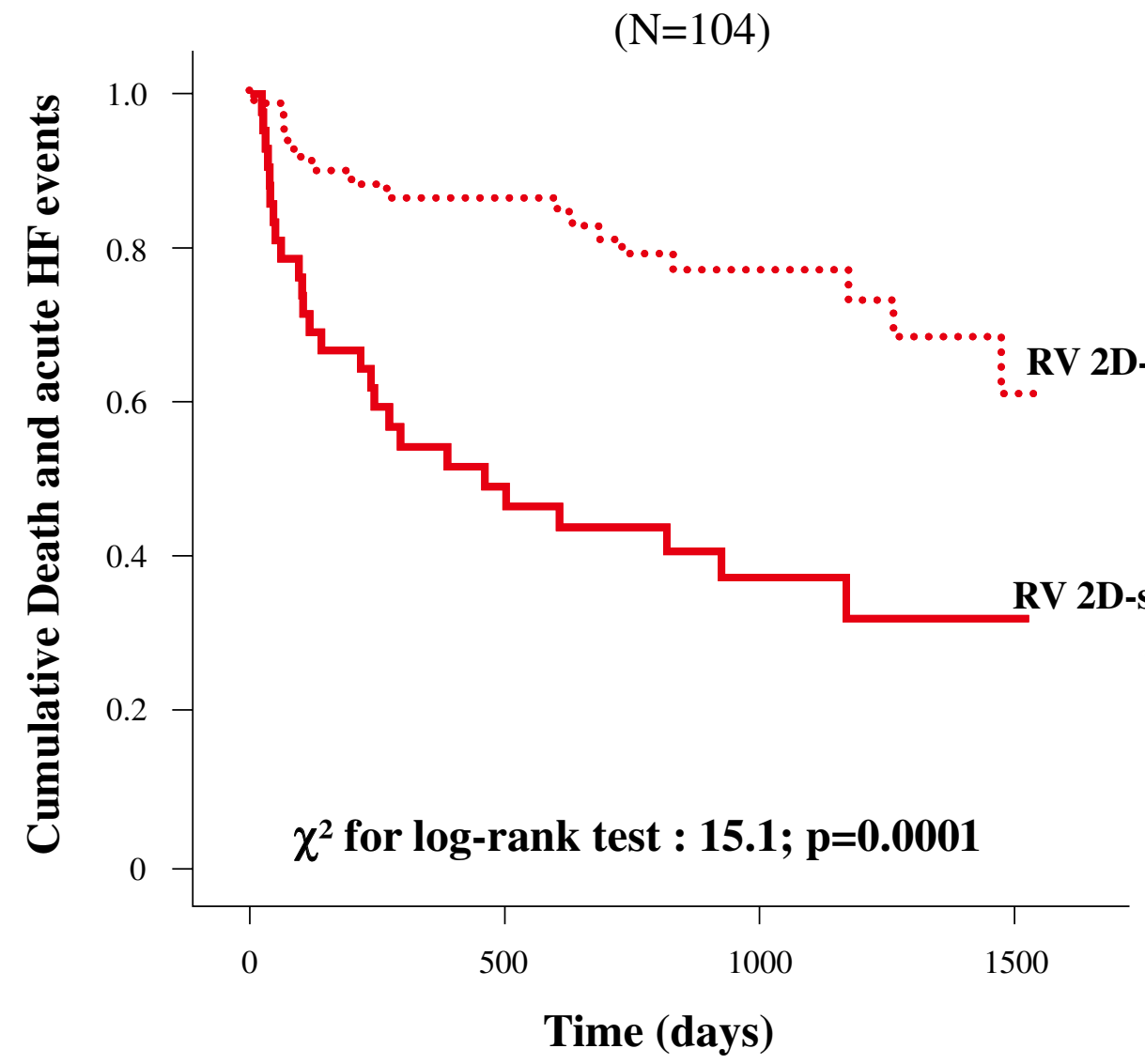

Figure 3. Kaplan-Meier curve of RV-2D strain divided by the threshold of $-21 \%$. CHF, chronic heart failure; HF, heart failure; RV, right ventricle.

off is shown in Figure 3.

\section{Reproducibility}

Intra-observer reproducibility was $8 \%$ for RV global longitudinal strain and $10 \%$ for strain rate. Corresponding values for interobserver reproducibility were $10 \%$ and $14 \%$, respectively.

\section{Discussion}

We showed that RV-2D strain correlated with standard echocardiographic parameters (TAPSE and peak velocity of tricuspid annular systolic motion by pulsed TDI) used to measure RV contractility. Among our controls, 96\% had RV-2D strain values lower than $-21 \%$. RV-2D strain was independently associated with the occurrence within 1 year of a composite endpoint (death, admission for acute heart failure, emergency cardiac transplantation, or emergency ventricular assist-device implantation). RV-2D strain values greater than $-21 \%(-21-0 \%)$ were at highest risk for experiencing the primary outcome within the first year.

\section{Echocardiographic Evaluation of RV Systolic Function}

The complex shape and marked load dependency of the RV create challenges when assessing RV function. ${ }^{2}$ Various echocardiographic surrogates for RV contractility have been described..$^{4,9,14}$

RV ejection fraction measurement using 2D echocardiography was the first echocardiographic method used to assess RV systolic function, ${ }^{15,16}$ but required numerous geometric assumptions that diminished the accuracy of the results and may explain why RV fractional area was not independently correlated to the prognosis in our study. Two other parameters were therefore developed: TAPSE ${ }^{4}$ and the peak velocity of tricuspid annular systolic motion measured using TDI. ${ }^{9}$ These 2 parameters merely estimate the annular longitudinal function of the RV free wall, based on displacement of the tricuspid ring relative to the transducer. More recently, TDI-based parameters reflecting myocardial deformation, such as strain and strain rate, were shown to be closely related to the intrinsic functional capacity of the RV myocardium and to be more sensitive than previous parameters to subtle changes in contractility. ${ }^{17,18}$ However, the angle dependency and absence of automatic measurement methods were major obstacles to the use of RV strain and strain rate. Since then, speckle tracking has been developed to image myocardial deformation as a means of assessing RV systolic function. Speckle tracking provides rapid and simultaneous quantification of both regional and global lateral RV systolic function, as longitudinal lateral (free wall) RV function generates $80 \%$ of the RV stroke volume. ${ }^{19}$ TDI and 2D strain-derived parameters have been found 
to be superior over conventional echocardiographic parameters in identifying patients with regional RV dysfunction. ${ }^{20}$ Furthermore, 2D strain is relatively angle-independent and independent of cardiac motion, in contrast to TAPSE. ${ }^{18} 2 \mathrm{D}$ strain is also easily measurable using automatic software.

\section{Prognostic Significance of RV Systolic Function in CHF and RV-2D Strain}

$\mathrm{RV}$ systolic function strongly predicts the occurrence of cardiac events in patients with CHF. ${ }^{3-5}$ In keeping with an earlier study in patients with acute myocardial infarction, ${ }^{21} \mathrm{RV}-2 \mathrm{D}$ strain was a strong predictor of our composite primary outcome in CHF patients. A cut-off of $-21 \%$ was optimal for separating patients with and without the primary outcome after 1 year of follow-up. Similar cut-offs were found using speckle tracking in patients with myocardial infarction $(-22.1 \%)^{21}$ or TDI-derived strain measurement in patients with arrhythmogenic RV cardiopathy $(-18.2 \%) .{ }^{20}$ It is worth noting that reported RV cut-offs are higher than the previously reported LV cut-off $(-9 \%) .^{10}$

Longitudinal motion can be quantified using either strain or strain rate. Strain rate is assumed to be load independent and superior to strain in assessing myocardial contractility and prognosis. In our study, however, RV-2D strain performed better than strain rate in predicting the primary outcome. We previously obtained a similar result when assessing the prognostic significance of LV systolic function in patients with unstable CHF. ${ }^{10}$ The superiority of 2D strain over strain rate may be related to the smaller amount of noise in the strain data, which facilitates identification of the peak.

BNP was also shown to be a strong marker of prognosis in our study. Several studies have demonstrated a correlation between BNP and LV filling pressure ${ }^{22}$ and that LV filling pressure correlates to prognosis. ${ }^{23}$ Our study demonstrated that $\mathrm{RV}-2 \mathrm{D}$ strain remained an independent marker of prognosis when BNP was added to the predictive model.

\section{Limitations of RV-2D Strain Measurement}

RV-2D strain was not measurable in $18(11 \%)$ of our 161 study participants. The RV basal segment was less often measurable than the apical or middle segment. In the controls, the basal RV segment was difficult to track when motion of this segment was substantial and directed not only anteriorly but also towards the septum. A similar difficulty occurred in $\mathrm{CHF}$ patients with major anterior systolic motion of the tricuspid annulus, usually related to elevated pulmonary artery pressure. ${ }^{11,12}$ In our study, we assessed longitudinal RV deformation and not radial RV deformation. When measured accurately, longitudinal deformation reflects global RV contractile function under baseline conditions and during acute load modulation, whereas circumferential motion is influenced by changes in afterload. ${ }^{24} \mathrm{RV}$ afterload or pulmonary vascular resistance (PVR) were not assessed in this study. PVR may significantly alter RV geometry and function, and contributes directly to poor outcome. A part of the interventricular septum may contribute to RV systolic function but it was not possible to measure it because of a software limitation RV ischemia can occur in patients with coronary artery disease, but the study was not powered to assess the consequences of RV ischemia on RV echocardiographic variables. Furthermore, longitudinal strain may be less sensitive to assess ischemia than other echocardiographic parameters. ${ }^{25}$

\section{Conclusion}

In this study, RV-2D strain reliably reflected RV systolic function. An RV-2D strain cut-off of $-21 \%$ was best for separating patients with and without the composite primary outcome after 1 year. These results suggest that the use of $2 \mathrm{D}$-strain to assess RV contractility should be encouraged in everyday clinical practice to better evaluate the prognosis of patients with $\mathrm{CHF}$.

\section{Acknowledgments}

Funding: No specific funding was received for this study. The authors of the study are full-time salaried employees of their respective institutions.

\section{Disclosures}

Conflict of Interest: None of the authors has any conflicts of interest to declare.

\section{References}

1. Haddad F, Hunt SA, Rosenthal DN, Murphy DJ. Right ventricular function in cardiovascular disease, part I: Anatomy, physiology, aging, and functional assessment of the right ventricle. Circulation 2008; 117: 1436-1448.

2. Haddad F, Doyle R, Murphy DJ, Hunt SA. Right ventricular function in cardiovascular disease, part II: Pathophysiology, clinical importance, and management of right ventricular failure. Circulation 2008; 117: $1717-1731$.

3. de Groote P, Millaire A, Foucher-Hossein C, Nugue O, Marchandise $\mathrm{X}$, Ducloux G, et al. Right ventricular ejection fraction is an independent predictor of survival in patients with moderate heart failure. $J$ Am Coll Cardiol 1998; 32: 948-954.

4. Ghio S, Recusani F, Klersy C, Sebastiani R, Laudisa ML, Campana $\mathrm{C}$, et al. Prognostic usefulness of the tricuspid annular plane systolic excursion in patients with congestive heart failure secondary to idiopathic or ischemic dilated cardiomyopathy. Am J Cardiol 2000; 85: $837-842$.

5. Di Salvo TG, Mathier M, Semigran MJ, Dec GW. Preserved right ventricular ejection fraction predicts exercise capacity and survival in advanced heart failure. J Am Coll Cardiol 1995; 25: 1143-1153.

6. Ghio S, Perlini S, Palladini G, Marsan NA, Faggiano G, Vezzoli M, et al. Importance of the echocardiographic evaluation of right ventricular function in patients with AL amyloidosis. Eur J Heart Fail 2007; 9: 808-813.

7. Kjaergaard J, Akkan D, Iversen KK, Kober L, Torp-Pedersen C, Hassager C. Right ventricular dysfunction as an independent predictor of short- and long-term mortality in patients with heart failure. Eur J Heart Fail 2007; 9: 610-616.

8. Meluzin J, Spinarova L, Bakala J, Toman J, Krejci J, Hude P, et al. Pulsed Doppler tissue imaging of the velocity of tricuspid annular systolic motion; a new, rapid, and non-invasive method of evaluating right ventricular systolic function. Eur Heart J 2001; 22: 340-348.

9. Damy T, Viallet C, Lairez O, Deswarte G, Paulino A, Maison P, et al. Comparison of four right ventricular systolic echocardiographic parameters to predict adverse outcomes in chronic heart failure. Eur J Heart Fail 2009; 11: 818-824.

10. Nahum J, Bensaid A, Dussault C, Macron L, Clemence D, Bouhemad $\mathrm{B}$, et al. Impact of longitudinal myocardial deformation on the prognosis of chronic heart failure patients. Circ Cardiovasc Imaging 2010; 3: $249-256$.

11. Giusca S, Jurcut R, Ginghina C, Voigt JU. The right ventricle: Anatomy, physiology and functional assessment. Acta Cardiol 2010; 65: $67-77$.

12. Jurcut R, Giusca S, La Gerche A, Vasile S, Ginghina C, Voigt JU. The echocardiographic assessment of the right ventricle: What to do in 2010? Eur J Echocardiogr 2010; 11: 81-96.

13. Lang RM, Bierig M, Devereux RB, Flachskampf FA, Foster E, Pellikka PA, et al. Recommendations for chamber quantification: A report from the American Society of Echocardiography's Guidelines and Standards Committee and the Chamber Quantification Writing Group, developed in conjunction with the European Association of Echocardiography, a branch of the European Society of Cardiology. J Am Soc Echocardiogr 2005; 18: 1440-1463.

14. Tugcu A, Yildirimtürk O, Tayyareci Y, Demiroglu C, Aytekin S. Evaluation of subclinical right ventricular dysfunction in obstructive sleep apnea patients using velocity vector imaging. Circ J 2010; 74: $312-319$. 
15. Watanabe T, Katsume H, Matsukubo H, Furukawa K, Ijichi H. Estimation of right ventricular volume with two dimensional echocardiography. Am J Cardiol 1982; 49: 1946-1953.

16. Bommer W, Weinert L, Neumann A, Neef J, Mason DT, DeMaria A. Determination of right atrial and right ventricular size by twodimensional echocardiography. Circulation 1979; 60: 91-100.

17. Donal E, Roulaud M, Raud-Raynier P, De Bisschop C, Leclercq C, Derumeaux G, et al. Echocardiographic right ventricular strain analysis in chronic heart failure. Eur J Echocardiogr 2007; 8: 449-456.

18. Giusca S, Dambrauskaite V, Scheurwegs C, D'Hooge J, Claus P, Herbots L, et al. Deformation imaging describes right ventricular function better than longitudinal displacement of the tricuspid ring. Heart 2010; 96: $281-288$.

19. Carlsson M, Ugander M, Heiberg E, Arheden H. The quantitative relationship between longitudinal and radial function in left, right, and total heart pumping in humans. Am J Physiol Heart Circ Physiol 2007; 293: H636-H644.

20. Teske AJ, Cox MG, De Boeck BW, Doevendans PA, Hauer RN, Cramer MJ. Echocardiographic tissue deformation imaging quantifies abnormal regional right ventricular function in arrhythmogenic right ventricular dysplasia/cardiomyopathy. J Am Soc Echocardiogr
2009; 22: 920-927.

21. Antoni ML, Scherptong RW, Atary JZ, Boersma E, Holman ER, van der Wall EE, et al. Prognostic value of right ventricular function in patients after acute myocardial infarction treated with primary percutaneous coronary intervention. Circ Cardiovasc Imaging 2010; 3: $264-271$.

22. Haug C, Metzele A, Kochs M, Hombach V, Grunert A. Plasma brain natriuretic peptide and atrial natriuretic peptide concentrations correlate with left ventricular end-diastolic pressure. Clin Cardiol 1993; 16: $553-557$.

23. Okura H, Kubo T, Asawa K, Toda I, Yoshiyama M, Yoshikawa J, et al. Elevated E/E' predicts prognosis in congestive heart failure patients with preserved systolic function. Circ J 2009; 73: 86-91.

24. Leather HA, Ama R, Missant C, Rex S, Rademakers FE, Wouters PF. Longitudinal but not circumferential deformation reflects global contractile function in the right ventricle with open pericardium. Am J Physiol Heart Circ Physiol 2006; 290: H2369-H2375.

25. Ishizu T, Seo Y, Baba M, Machino T, Higuchi H, Shiotsuka J, et al. Impaired subendocardial wall thickening and post-systolic shortening are signs of critical myocardial ischemia in patients with flowlimiting coronary stenosis. Circ J 2011; 75: 1934-1941. 